\title{
The effect of limitation of joint motion range due to ankle taping on the evaluation of functional motion of high school Judo athletes
}

\author{
Won-Jin Kim', Tae-Beom Seo ${ }^{2}$, Jong-Baek Lee ${ }^{3, *}$ \\ 1Department of Physical Education, Graduate School, Youngin University, Youngin, Korea \\ 2Department of Physical Education, Jeju National University, Jeju, Korea \\ ${ }^{3}$ Department of Exercise \& Sport Science, Center for Sport Science in Gangwon, Chuncheon, Korea
}

The purpose of this study is to investigate the effect of ankle injury preventative $\mathrm{C}$-tape on the ankle range of motion, Y-balance test (YBT), and functional movement screening (FMS) test in Judo athletes. Participants in this study were 15 male judo athletes in high school. The angle of the ankle joint, YBT, and FMS were examined with and without the application of C-tape on each athlete's dominant foot. In YBT, ankle range of motion, and anterior reach distance were significantly lower in the taped ankle compared to the other $(P<0.01)$. Moreover, the overhead deep squat and the FMS total score were significantly decreased after the $\mathrm{C}$-tape application $(P<0.05)$. The taping's limitation on the ankle joint range of motion may impose adverse effects on the other relevant joints, therefore a proper guideline on long-term usage is advised.

Keywords: Ankle taping, Y-balance test, Functional movement screen, Range of motion, High school Judo athletes

\section{INTRODUCTION}

Lower extremities injury is the most common injury in most of the sports (Hootman et al., 2007). Especially, the ankle region injury is shown to be the common, making up more than $50 \%$ of sport injury (Czajka et al., 2014). Judo is the martial art with the highest percentage of injuries during the games and practices. Injuries that disrupted training occurred in $56 \%$ of judokas and most common injuries in judo were "ankle sprains and joint injuries" (4.98\% and 3.98\%). (Garcia-Isidoro et al., 2021). Due to the high recurrence of injury even after the treatment which may bring catastrophic effect on the athlete, careful management is required (Yammine and Assi, 2018). Various approaches have been researched for its prevention and treatment, the application of sport tape or brace are known to be effective in prevention of the ankle injury (Jelinek et al., 2019). The application of taping has been largely utilized as a preventative measure for the ankle injury (Kaminski et al., 2013).

The application of nonelastic tape on the injured joint is more of preventative measure as it reduces the external force exerted on the joint, and protect the damaged joint by limiting the range of motion (ROM). The ankle $\mathrm{C}$-tape is reported to diminish the recurrent injury rate, improve proprioception while having no adverse effect on exercise performance in the most of tests, with minimal disadvantages on other joints (Callaghan et al., 2012).

On the other hand, Kaminski et al. (2013) on the exercise and kinematic analysis reported that the ankle $\mathrm{C}$-tape may conflicts negative effect on the metatarsal of the foot, while the other study reported that it may affect the foot movement during the running motion (Sato et al., 2019). It was pointed out that a condition which body mass has no load on the joint is required, to realistically have the preventative effect of taping on exercise performance (Simon and Donahue, 2013). As noted, conflicting results are reported on the application of $\mathrm{C}$-tape.
${ }^{*}$ Corresponding author: Jong-Baek Lee iD https://orcid.org/0000-0001-8276-2057 Department of Exercise \& Sport Science, Center for Sport Science in Gangwon, 80 Sports town-gil, Chuncheon 24239, Korea

Email: supertomcat100@hanmail.net

Received: April 2, 2021 / Accepted: May 8, 2021
This is an Open Access article distributed under the terms of the Creative Commons Attribution Non-Commercial License (https://creativecommons.org/licenses/by-nc/4.0/) which permits unrestricted non-commercial use, distribution, and reproduction in any medium, provided the original work is properly cited. 
However, as the human's kinetic chain is a single system that is composed of different body parts influencing each other, the study on the ankle ROM limitation's effect on ankle peripheral tissues, joints and the exercise performance induced by the ankle $\mathrm{C}$-tape is limited (Karandikar and Vargas, 2011). In order to objectively assess the movement-related exercise performance of the athletes, our study utilized Y-balance test (YBT) and functional movement screening (FMS) method. These simple, efficient methods with high reliability are widely used in the sport field as one of the management tools. The purpose of this study is to investigate the effect of temporary ankle ROM limitation by $\mathrm{C}$-tape application on the movement-related exercise performance, and to utilize its result as a baseline data in proper practice of $\mathrm{C}$-tape application.

\section{MATERIALS AND METHODS}

\section{Participants}

Fifteen male high school judo athletes from Seoul Physical Education high school located in Seoul, Republic of Korea participated in this study. Before the experiment, the purpose of the study and the experimental method were explained in detail to the subjects, and the test was conducted only for the subjects who voluntarily participated in the experiment. The general characteristics of the participants are as in Table 1 . The widely used injury preventative taping technique to fix the ankle in soccer, basketball, and other sports are adopted in this study. We referred to study by Konor et al. (2012) to measure the angle of the ankle. The specific C-tape technique and angle ankle measurement method are as the following. Fifteen participants completed the YBT and FMS measurements with no tape and with C-tape, respectively.

\section{C-tape application technique}

We attached the sponge tapes on 2-3 folds on surface prior to the $\mathrm{C}$-tape application to prevent skin damage. First, the anchortape was applied on the end of ankle and dorsum of foot to fix the

Table 1. Characteristic of the subjects $(n=15)$

\begin{tabular}{lc}
\hline Variable & Mean \pm SD \\
\hline Age $(\mathrm{yr})$ & $17.7 \pm 0.7$ \\
Height $(\mathrm{cm})$ & $173.5 \pm 6.7$ \\
Weight $(\mathrm{kg})$ & $82.4 \pm 21.6$ \\
Exercise careers $(\mathrm{mo})$ & $72 \pm 18.7$ \\
\hline
\end{tabular}

SD, standard deviation. underlab tape in place. Second, the tape was applied repetitively from medial to lateral ankle and taped starting from the heel to the dorsum of foot in horse-shoe shape to prevent left-right movement. Third, taping was applied starting from medial side of foot through the bottom covering the ankle and the dorsum to fix the ankle, and lastly, finished the taping by tiding up the ankle surrounding surface.

\section{Ankle angle measurement}

The participant was instructed to align the knee with the second toe, with the hallux to be $10 \mathrm{~cm}$ apart from the wall. Only using two fingers on each hand were used to maintain the balance supporting the wall. We instructed the participants' knee to contact the wall, and controlled the distance based on the extent of the heel coming off the ground. The inclinometer was placed on the upper anterior tibialis tubercle. The goniometer was used to measure the ankle angle based on the center part between the tibia and malleolus.

\section{Y balance test}

The $\mathrm{Y}$ balance test (Move2Perform, Evansville, IN, USA) is a simplified version of the star excursion balance test and utilized in various sports field to assess the risk of injury and dynamic balances in athletes. Based on its high retest reliability and efficacy, a number of researches are being conducted. Although both upper and lower extremities can be measured, only the lower extremities measurement was applied in the current study. The assessment was made and utilized by rating the maximal foot reach distance anterior, posterolateral, posteromedial and so on in order, while having the participant to fix one foot as an axis.

\section{Functional movement screening}

FMS test kit (Functional Movement System, Chatham, VA, USA) was created by Gray Cook and his colleagues in 1997 incorporating the movements and injury assessment and have been studied hypothesizing its correlation with risk of injury and exercise performances in athletic population. It is composed of seven different movements (overhead deep squat, hurdle step, in-line lunge, shoulder mobility, active straight leg raise, trunk stability push-up, rotary stability), and each movement is rated on scale of 0 to 3 by the tester. It is rated 0 if the participant feels a pain during the assessment, rated 1 if the movement cannot be executed, rated 2 if the participant can execute the compensation movement after each motion. It is rated 3 if the participant can execute defined movement correctly (Cook et al., 2006). 


\section{Statistical analysis}

This study used IBM SPSS Statistics ver. 23.0 (IBM Co., Armonk, NY, USA) in statistical analysis of the collected data on 15 male judo athletes from Seoul Physical Education high school located in Seoul, comparing two groups with and without the C-tape application on an ankle. Two-way repeated measures analysis of variance (ANOVA) was done to compare the changes in YBT score of the participants in $\mathrm{C}$-tape experimental group and control group before and after the application of $\mathrm{C}$-tape. Paired $t$-test was conducted only on the experimental group's FMS to compare the preand post-C-tape application. The significance level was set at 0.05 $(P<0.05)$.

\section{RESULTS}

\section{Changes in ankle ROM}

The result of descriptive analysis and two-way ANOVA with repeated measures to examine the improvement effect on ankle ROM before and after the $\mathrm{C}$-tape application in the experimental and control group are in Tables 2 and 3. As Table 2 illustrates, the ankle ROM in the pre-application of C-tape was $53.80 \pm 3.23$, $57.60 \pm 2.97$ in the postapplication experimental group. In control group, the preapplication ankle ROM was $52.73 \pm 3.58$, and $53.88 \pm$

Table 2. Descriptive statistics of changes in ankle angle before and after ankle taping

\begin{tabular}{lclcl}
\hline Variable & Repeated & Factor & No. & Mean \pm SD \\
\hline Ankle angle & Pre & ATG & 15 & $53.80 \pm 3.23$ \\
& & CG & 15 & $53.73 \pm 3.58$ \\
& Total & 30 & $53.77 \pm 3.35$ \\
& Post & ATG & 15 & $57.60 \pm 2.97$ \\
& CG & 15 & $53.33 \pm 3.87$ \\
& & Total & 30 & $55.47 \pm 4.02$ \\
\hline
\end{tabular}

SD, standard deviation; ATG, ankle taping group; CG, control group.
3.87 in the postapplication (mean \pm standard deviation [SD]).

There was no significant difference between group analysis $(F=$ 3.290, $P=0.080$ ), while the ankle angle in the post-application of C-tape was turned out to be significantly higher compared to the pre-application condition $(F=20.573, P=0.001)$. Between-group analysis examining of interactive effect of the pre- and postapplication on the ankle ROM, a significant level of interactive effect was detected ( $F=31.393, P=0.001$ ). This result represents that the ankle angle is significantly higher in $\mathrm{C}$-tape experimental group compared to the control group due to the $\mathrm{C}$-tape application.

\section{Changes in anterior reach distance in YBT}

The result of descriptive analysis and two-way ANOVA with repeated measures to examine the improvement effect on anterior reach distance (ARD) in YBT pre- and postapplication of C-tape in both groups are in Tables 4 and 5. As Table 4 illustrates, the mean \pm SD value in the experimental group's ARD in preapplication is $59.13 \pm 6.71$, and $51.47 \pm 6.94$ in the postapplication condition. In the control group, the preapplication ARD value was $59.80 \pm 6.54$, and $57.69 \pm 5.62$ in the postapplication condition.

Based on the difference analysis, there was no significantly difference between groups $(F=2.825, P=0.104)$, while the ARD turned out to be decreased in comparison between the pre- and postapplication of $\mathrm{C}$-tape $(F=5.563, P=0.026)$. In the analysis between groups, and pre- and postapplication of $\mathrm{C}$-tape interactive effect on ARD, the experimental group showed significant level of interactive effect in lower ARD in the postapplication condition compared to the control group.

\section{Changes in posterolateral reach distance of YBT}

The result of descriptive analysis and two-way ANOVA with repeated measures to examine the improvement effect posterolateral reach distance (PLRD) in YBT pre- and postapplication of C-tape in both groups are in Tables 6 and 7. As Table 6 illustrates,

Table 3. Two-way repeated measures analysis of variance of changes in ankle angle before and after ankle taping

\begin{tabular}{|c|c|c|c|c|c|c|c|}
\hline Variable & Source of variance & SS & $d f$ & MS & $F$ & $P$-value & $\eta^{2}$ \\
\hline \multirow[t]{6}{*}{ Ankle angle } & Pre/post & 43.350 & 1 & 43.350 & 20.573 & $0.000^{*}$ & 0.424 \\
\hline & Pre/pos group & 66.150 & 1 & 66.150 & 31.393 & $0.000^{*}$ & 0.529 \\
\hline & Error (pre/post) & 59.000 & 28 & 2.107 & - & - & - \\
\hline & Intercept & $178,978.820$ & 1 & $178,978.820$ & 8,362.566 & $0.000^{*}$ & 0.997 \\
\hline & Group & 70.417 & 1 & 70.417 & 3.290 & 0.080 & 0.105 \\
\hline & Error & 599.267 & 28 & 21.402 & - & - & - \\
\hline
\end{tabular}

SS, sum of squares; $d f$, degrees of freedom; MS, mean square; $\eta^{2}$, partial eta-squared [SSeffect/(SSeffect+SSerror)]. ${ }^{*} P<0.05$. 
Table 4. Descriptive statistics of changes in anterior reach distance before and after ankle taping

\begin{tabular}{lclcl}
\hline Variable & Repeated & Factor & No. & Mean \pm SD \\
\hline Anterior reach & Pre & ATG & 15 & $59.13 \pm 6.71$ \\
distance & & CG & 15 & $59.80 \pm 6.54$ \\
& & Total & 30 & $59.47 \pm 6.52$ \\
& Post & ATG & 15 & $51.47 \pm 6.94$ \\
& CG & 15 & $57.69 \pm 5.62$ \\
& Total & 30 & $54.58 \pm 6.97$ \\
\hline
\end{tabular}

SD, standard deviation; ATG, ankle taping group; CG, control group.
Table 6. Descriptive statistics of changes in posterolateral reach distance before and after ankle taping

\begin{tabular}{lclcl}
\hline Variable & Repeated & Factor & No. & Mean \pm SD \\
\hline Posterolateral & Pre & ATG & 15 & $89.27 \pm 11.37$ \\
reach distance & & CG & 15 & $88.69 \pm 8.32$ \\
& & Total & 30 & $88.98 \pm 9.79$ \\
& Post & ATG & 15 & $80.73 \pm 12.07$ \\
& & CG & 15 & $81.56 \pm 8.99$ \\
& & Total & 30 & $81.14 \pm 10.46$ \\
\hline
\end{tabular}

SD, standard deviation; ATG, ankle taping group; CG, control group.

Table 5. Two-way repeated measures analysis of variance of changes in anterior reach distance before and after ankle taping

\begin{tabular}{|c|c|c|c|c|c|c|c|}
\hline Variable & Source of variance & SS & $d f$ & MS & $F$ & $P$-value & $\eta^{2}$ \\
\hline \multirow{6}{*}{$\begin{array}{l}\text { Anterior reach } \\
\text { distance }\end{array}$} & Pre/post & 358.519 & 1 & 358.519 & 17.233 & $0.001^{*}$ & 0.381 \\
\hline & Pre/post group & 115.741 & 1 & 115.741 & 5.563 & $0.026^{*}$ & 0.166 \\
\hline & Error (pre/post) & 582.519 & 28 & 20.804 & - & - & - \\
\hline & Intercept & $195,092.030$ & 1 & $195,092.030$ & $3,096.491$ & $0.001^{*}$ & 0.991 \\
\hline & Group & 177.963 & 1 & 177.963 & 2.825 & 0.104 & 0.092 \\
\hline & Error & $1,764.119$ & 28 & 63.004 & - & - & - \\
\hline
\end{tabular}

SS, sum of squares; $d f$, degrees of freedom; MS, mean square; $\eta^{2}$, partial eta-squared [SSeffect/(SSeffect+SSerror)].

${ }^{*} P<0.05$.

Table 7. Two-way repeated measures analysis of variance of changes in posterolateral reach distance before \& after ankle taping

\begin{tabular}{llrrrrrr}
\hline Variable & Source of variance & \multicolumn{1}{c}{ SS } & df & MS & $F$ & $P$-value & $\eta^{2}$ \\
\hline Posterolateral reach & Pre/post & 920.417 & 1 & 920.417 & 13.576 & $0.001^{*}$ & 0.327 \\
distance & Pre/post group & 7.350 & 1 & 7.350 & 0.108 & 0.744 & - \\
& Error (pre/post) & $1,898.289$ & 28 & 67.796 & - & -004 & - \\
& Intercept & $434,123.560$ & 1 & $434,123.560$ & $3,001.474$ & $0.000^{*}$ & 0.991 \\
& Group & 0.224 & 1 & 0.224 & 0.002 & 0.969 & - \\
& Error & $4,049.830$ & 28 & 144.637 & - & -000 \\
\hline
\end{tabular}

SS, sum of squares; df, degrees of freedom; MS, mean square; $\eta^{2}$, partial eta-squared [SSeffect/(SSeffect+SSerror)].

${ }^{*} P<0.05$.

the mean \pm SD value in the experimental group's PLRD in preapplication is $89.27 \pm 8.32$, and $80.73 \pm 12.07$ in the postapplication condition. In the control group, the preapplication PLRD value was $88.69 \pm 8.32$, and $81.56 \pm 8.99$ in the postapplication condition.

Based on the difference analysis, no difference was detected at significant level between groups ( $F=002, P=0.969)$, while the PLRD turned out to be decreased in comparison between the preand postapplication of $\mathrm{C}$-tape $(F=13.576, P=0.001)$. In the analysis between groups, and pre- and postapplication of $C$-tape interactive effect on PLRD, no interaction effect was detected at significant level $(F=0.108, P=0.744)$. Both experimental and control group showed decreased PLRD in the second measurement con- dition with no effect C-tape application.

\section{Changes in posteromedial reach distance of YBT}

The result of descriptive analysis and two-way ANOVA with repeated measures to examine the improvement effect posteromedial reach distance (PMRD) in YBT pre- and postapplication of C-tape in both groups are in Tables 8 and 9. As Table 8 illustrates, the mean \pm SD value in the experimental group's PMRD in preapplication is $85.71 \pm 11.02$ and $72.91 \pm 9.86$ in the postapplication condition. In the control group, the preapplication PMRD value was $84.78 \pm 11.72$ and $75.84 \pm 12.02$ in the postapplication condition.

Based on the difference analysis, no difference was detected at 
Table 8. Descriptive statistics of changes in posteromedial reach distance before and after ankle taping

\begin{tabular}{lclll}
\hline Variable & Repeated & Factor & No. & Mean \pm SD \\
\hline $\begin{array}{l}\text { Posteromedial } \\
\text { reach distance }\end{array}$ & Pre & ATG & 15 & $85.71 \pm 11.02$ \\
& & CG & 15 & $84.78 \pm 11.72$ \\
& & Total & 30 & $85.24 \pm 11.19$ \\
& Post & ATG & 15 & $72.91 \pm 9.86$ \\
& & CG & 15 & $75.84 \pm 12.02$ \\
& & Total & 30 & $74.38 \pm 10.90$ \\
\hline
\end{tabular}

SD, standard deviation; ATG, ankle taping group; CG, control group.
Table 10. Descriptive statistics of changes in composite reach distance before and after ankle taping

\begin{tabular}{|c|c|c|c|c|}
\hline Variable & Repeated & Factor & No. & Mean \pm SD \\
\hline \multirow{6}{*}{$\begin{array}{l}\text { Composite } \\
\text { reach distance }\end{array}$} & \multirow[t]{3}{*}{ Pre } & ATG & 15 & $80.29 \pm 7.86$ \\
\hline & & CG & 15 & $79.97 \pm 6.68$ \\
\hline & & Total & 30 & $80.13 \pm 7.17$ \\
\hline & \multirow[t]{3}{*}{ Post } & ATG & 15 & $70.39 \pm 7.82$ \\
\hline & & $\mathrm{CG}$ & 15 & $73.83 \pm 7.34$ \\
\hline & & Total & 30 & $72.11 \pm 7.65$ \\
\hline
\end{tabular}

SD, standard deviation; ATG, ankle taping group; CG, control group.

Table 9. Two-way repeated measures analysis of variance of changes in posteromedial reach distance before and after ankle taping

\begin{tabular}{|c|c|c|c|c|c|c|c|}
\hline Variable & Source of variance & SS & $d f$ & MS & $F$ & $P$-value & $\eta^{2}$ \\
\hline \multirow{6}{*}{$\begin{array}{l}\text { Posteromedial } \\
\text { reach distance }\end{array}$} & Pre/post & $1,771.267$ & 1 & $1,771.267$ & 45.926 & $0.000^{*}$ & 0.621 \\
\hline & Pre/post group & 56.067 & 1 & 56.067 & 1.454 & 0.238 & 0.049 \\
\hline & Error (pre/post) & $1,079.889$ & 28 & 38.567 & - & - & - \\
\hline & Intercept & $382,188.810$ & 1 & $382,188.810$ & $1,805.456$ & $0.000^{*}$ & 0.985 \\
\hline & Group & 15.000 & 1 & 15.000 & 0.071 & 0.792 & 0.003 \\
\hline & Error & $5,927.193$ & 28 & 211.685 & - & - & - \\
\hline
\end{tabular}

SS, sum of squares; $d f$, degrees of freedom; MS, mean square; $\eta^{2}$, partial eta-squared [SSeffect/(SSeffect+SSerror)]. ${ }^{*} P<0.05$.

Table 11. Two-way repeated measures analysis of variance of changes in composite reach distance before and after ankle taping

\begin{tabular}{llrrrrrr}
\hline Variable & Source of variance & \multicolumn{1}{c}{ SS } & df & MS & F & P-value & $\eta^{2}$ \\
\hline Composite reach & Pre/post & 964.270 & 1 & 964.270 & 37.055 & $0.000^{*}$ & 0.570 \\
distance & Pre/post group & 53.092 & 1 & 53.092 & 2.040 & 0.164 & - \\
& Error (pre/post) & 728.631 & 28 & 26.023 & - & - & - \\
& Intercept & $34,7671.700$ & 1 & $347,671.700$ & $4,107.783$ & $0.000^{*}$ & 0.993 \\
& Group & 36.341 & 1 & 36.341 & 0.429 & 0.518 & -0.015 \\
& Error & $2,369.845$ & 28 & 84.637 & - & - \\
\hline
\end{tabular}

SS, sum of squares; $d f$, degrees of freedom; MS, mean square; $\eta^{2}$, partial eta-squared [SSeffect/(SSeffect+SSerror)]. ${ }^{*} P<0.05$.

significant level between groups ( $F=0.071, P=0.792)$, while the PMRD turned out to be decreased in comparison between the pre- and postapplication of $\mathrm{C}$-tape $(F=45.926, P=0.001)$. In the analysis between groups, and pre- and postapplication of $\mathrm{C}$-tape interactive effect on PMRD, no interaction effect was detected at significant level $(F=1.454, P=0.238)$. Both experimental and control group showed decreased PMRD in the second measurement condition with no effect $\mathrm{C}$-tape application.

\section{Changes in composite reach distance of YBT}

The result of descriptive analysis and two-way ANOVA with repeated measures to examine the improvement effect composite reach distance (CRD) in YBT pre- and postapplication of C-tape in both groups are in Tables 10 and 11. As Table 10 illustrates, the mean $\pm \mathrm{SD}$ value in the experimental group's $\mathrm{CRD}$ in pre-application is $80.29 \pm 7.86$, and $70.39 \pm 7.82$ in the postapplication condition. In the control group, the preapplication CRD value was $79.97 \pm 6.68$ and $73.83 \pm 7.34$ in the postapplication condition.

Based on the difference analysis, no difference was detected at significant level between groups ( $F=0.429, P=0.518$ ), while the CRD turned out to be significantly decreased in comparison between the pre- and post-application of $\mathrm{C}$-tape $(F=37.055, P=$ $0.001)$. In the analysis between groups and pre- and postapplication of $\mathrm{C}$-tape interactive effect on CRD, no interaction effect was detected at significant level $(F=2.040, P=0.164)$. Both experimental and control group showed decreased CRD in the second 
Table 12. Paired t-test of changes in FMS before and after ankle taping

\begin{tabular}{lccccc}
\hline Variable & Pre & Post & Paired differences & $t$ & $P$-value \\
\hline ODST & $2.13 \pm 0.52$ & $1.67 \pm 0.49$ & $0.47 \pm 0.83$ & 2.168 & $0.048^{*}$ \\
HST & $2.40 \pm 0.74$ & $1.93 \pm 0.70$ & $0.467 \pm 0.99$ & 1.825 & 0.089 \\
ILT & $2.93 \pm 0.26$ & $3.00 \pm 0.00$ & $-0.067 \pm 0.26$ & -1.000 & 0.334 \\
FMS total score & $17.20 \pm 1.61$ & $16.07 \pm 1.71$ & $1.13 \pm 1.69$ & 2.605 & $0.021^{*}$ \\
\hline
\end{tabular}

Values are presented as mean \pm standard deviation.

FMS, functional movement screening; ODST, overhead deep squat test; HST, hurdle step test; ILT, in-line lunge test.

${ }^{*} P<0.05$.

measurement condition with no effect C-tape application.

\section{Changes in FMS test}

The result of descriptive analysis and paired $t$-test is in Table 12 . As Table 12 illustrates, the FMS total score $(t=2.605, P=0.021)$, and overhead deep squat test (ODST) $(t=2.168, P=0.048)$ significantly decreased in the postapplication of $\mathrm{C}$-tape condition (FMS total score $=16.07 \pm 1.71$, ODST $=1.67 \pm 0.49)$ compared to the preapplication condition (FMS total score $=17.20 \pm 1.61$, ODST $=2.13 \pm 0.52$ ).

\section{DISCUSSION}

The injury in ankle region constitutes more than $80 \%$ of all sport injury, specifically being the most common injury taking up $32.3 \%$ in sport of Judo, which has higher rate of external trauma. Various studies have been conducted in ankle injury rehabilitation and treatment, and the application of taping or usage of braces are considered as the most effective preventative measure (Jelinek et al., 2019). Based on Sato et al. (2013) study which analyzed the squatting motion in 2-dimensional level, $1^{\circ}$ change of ankle angle induces $7^{\circ}$ of knee flexion angle difference, and Alpkaya and Koceja (2007) reported that the jump performance was decreased as angle ROM was reduced. Basnett et al. (2013) moreover, reported impaired balance ability in participants with low ankle ROM. Although the ankle region's dorsiflexion ROM limitation is known to affect the other joints movement and the exercise performances, the study and information on how the application of taping as of an injury preventative measure limits the ankle ROM and its influence on the movement is limited.

Therefore, the purpose of this study is to examine the effect of application of C-tape on FMS, YBT, the kinetic chain and to utilize its result as baseline data for proper application of taping as an injury preventative measure. Based on the purpose of this study, we temporarily limited the dominant ankle ROM in athletes us- ing C-tape and investigated it affects the movement of the athletes. To assess the movement of athletes in objective and quantitative manner, YBT and FMS tool were adopted. YBT is an improved version of star excursion balance test which revised the complexity and nonquantitative aspect, requiring shorter testing time with higher repeatability. Furthermore, with high intrarater reliability (intraclass correlation coefficient $[$ ICC $]=0.88-0.99$ ), YBT is mentioned as an effective assessment tool (Shaffer et al., 2013). In the study that looked at high school basketball, and college football players, the athletes with low YBT score or major asymmetry are reported with higher risk of injury (Lehr et al., 2013). Also, the athletes with chronic ankle injury, femoral compartment syndrome, or anterior crucial ligament injury could be identified with YBT (Boyle et al., 2016; Bulow et al., 2019).

FMS displays total seven basic bodily movements patterns requiring flexibility, mobility and stability in different levels (Cook et al., 2006). A number of researches are currently conducted on the relationship between FMS and injury in athletes and occupational clusters where physical activity is crucial (Butler et al., 2013; O'Connor et al., 2011). It is also widely used by strength and conditioning experts in decision of return to play, injury management, and prediction of injury in athletes by assessing the ability to execute the defined movement which is related to the kinetic chain (Clifton et al., 2015).

By limiting ankle ROM with the application of C-tape, the postapplication score of two movements assessment tool, ankle ROM and ARD in YBT, and FMS ODST, and FMS total score were decreased in significantly level $(P<0.05)$. Also, there was a trend that is not significant, where the taped ankle's PLRD, PMRD, and CRD decreased compared to the nontaped ankle in YBT. The ARD includes the main foot movement of dorsiflexion and plantar flexion, which requires higher activation of knee extensor, or quadriceps femoris rather than the muscles around the ankle joint (Walaszek et al., 2017). Furthermore, the muscle activation around hip joint are known to affect CRD, PLRD, and PMRD in YBT 
(Wilson et al., 2018). Overmoyer and Reiser in 2015 noted that the dorsiflexion of ankle is the most important factor in ARD, and small changes in ankle ROM can hugely impact dorsiflexion and plantarflexion.

This current study also found significantly lower ankle ROM on the C-tape applied side of ankle, and it can explain the statistically significant lower ARD in the C-tape applied ankle. On the same manner, the ankle ROM was more impactful on the dorsiflexion ROM compared to the plantarflexion. Based on Walaszek et al. (2017) and the study of Overmoyer and Reiser (2015), it was noted that the hip flexion and plantarflexion had higher effect on PLRD, PMRD, and CRD, which may explain how the current study did not show significant change in PLRD, PMRD, and CRD due to the impact only in ankle dorsiflexion ROM.

In FMS assessment, the ODST score was significantly lower in the postapplication of $\mathrm{C}$-tape condition. The ODST assessment tool can provide information of core stability, extremity mobility of hip, knee and ankle joint in symmetric position (Bhanot et al., 2019). It allows the assessment of left and right symmetry, and the sagittal plane mobility of hip, shoulder, knee, and ankles, and the limitation of ankle ROM affected knee, hip and shoulder joint in order.

Stiffler et al. (2015) research found that individuals who experienced dysfunction during an overhead squat also had reduced ankle dorsiflexion, increased pronation, and larger Q-angles. In this study, the limitation of dorsiflexion of the ankle joint is considered to be consistent with these findings. The hurdle step test is an assessment tool of walking motion's functional compensation movement or asymmetry. It evaluates the back and forth movement in sagittal plane, and left and right symmetry in coronal plane, demanding stable diagonal symmetric movement between each side of hip joint. The stability and mobility of hip, knee and ankle joint are important factors in the same manner with ODST (Lloyd et al., 2015). However, the hurdler step test requires the hip joint's flexion, extension, flexibility, and stability of balancing leg rather than the ankle angle, which can explain relatively lower effect of ankle ROM limitation with C-tape on the test.

The in-line lunge test (ILT) utilizes the movement deceleration, and change of direction aspects of sports, evaluating the hip, knee, and ankle joint mobility and stability, and the trunk control ability. The in-line lunge of the FMS evaluates lateral stability, balance, and movement asymmetries. Athletes who score poorly on the inline lunge should avoid activities requiring power or speed until scores are improved. Performance on the FMS in-line lunge was not related to balance (Hartigan et al., 2014). The reason why the
ILT was not related to balance ability or limitation of the ankle joint is considered to be the reason that no significant difference was found in the results of this study. The results of ODST, HST, and ILT, which showed no significant difference but decreased average value may explain the lower total FMS score in the C-tape postapplication condition.

The total FMS score is decreased in the C-tape postapplication condition, due to the factor that showed reduced mean value while having no significant differences not only in ODST which displayed statistical significance, but also in HST, and ILT. Furthermore, the foundation and the reduction in the ankle joint are indirectly explaining its effect on the FMS, which is congruent with Minick et al. (2010) that noted the reliability and sensitivity of FMS can spell out the change in FMS total score. In this study, the application of C-tape affected the ankle dorsiflexion ROM, which influenced the ARD in YBT, and ODST in FMS.

The players with $Y$ balance total score lower than certain threshold are reported with 6.5 times higher risk of injury during the season. The tightness in the soleus and gastrocnemius during dorsiflexion increases the knee valgus, which is again associated with higher risk of injury (Macrum et al., 2012; Sutton and Bullock, 2013). Based from those literatures and this study, it is thought that the limitation of ankle ROM may have a negative effect on other lower limb joints. In this study, only the effect of taping on the movement immediately after application was studied, and follow-up studies related to the change of the ankle angle and exercise performance according to the taping application time are considered to be necessary.

\section{CONFLICT OF INTEREST}

No potential conflict of interest to this article was reported.

\section{ACKNOWLEDGMENTS}

The authors received no financial support for this article.

\section{REFERENCES}

Alpkaya U, Koceja D. The effects of acute static stretching on reaction time and force. J Sports Med Phys Fitness 2007;47:147-150.

Basnett CR, Hanish MJ, Wheeler TJ, Miriovsky DJ, Danielson EL, Barr JB, Grindstaff TL. Ankle dorsiflexion range of motion influences dynamic balance in individuals with chronic ankle instability. Int J Sports Phys Ther 2013;8:121-128. 
Bhanot K, Kaur N, Brody LT, Bridges J, Berry DC, Ode JJ. Hip and trunk muscle activity during the star excursion balance test in healthy adults. J Sport Rehabil 2019;28:682-691.

Boyle MJ, Butler RJ, Queen RM. Functional movement competency and dynamic balance after anterior cruciate ligament reconstruction in adolescent patients. J Pediatr Orthop 2016;36:36-41.

Bulow A, Anderson JE, Leiter JR, MacDonald PB, Peeler J. The modified star excursion balance and Y-balance test results differ when assessing physically active healthy adolescent females. Int J Sports Phys Ther 2019;14:192-203.

Butler RJ, Contreras M, Burton LC, Plisky PJ, Goode A, Kiesel K. Modifiable risk factors predict injuries in firefighters during training academies. Work 2013;46:11-17.

Callaghan MJ, McKie S, Richardson P, Oldham JA. Effects of patellar taping on brain activity during knee joint proprioception tests using functional magnetic resonance imaging. Phys Ther 2012;92:821-830.

Clifton DR, Grooms DR, Onate JA. Overhead deep squat performance predicts functional movement screen ${ }^{\mathrm{TM}}$ score. Int J Sports Phys Ther 2015;10:622-627.

Cook G, Burton L, Hoogenboom B. Pre-participation screening: the use of fundamental movements as an assessment of function - part 1. N Am J Sports Phys Ther 2006;1:62-72.

Czajka CM, Tran E, Cai AN, DiPreta JA. Ankle sprains and instability. Med Clin North Am 2014;98:313-329.

Garcia-Isidoro S, Miguel-Tobal F, Martin-Escudero P, Gutierrez-Ortega C, Castellanos-Sanchez VO. Martial arts injuries: a longitudinal study about judo, karate and wushu carried out in the Community of Madrid, Spain. J Sports Med Phys Fitness 2021;61:244-251.

Hartigan EH, Lawrence M, Bisson BM, Torgerson E, Knight RC. Relationship of the functional movement screen in-line lunge to power, speed, and balance measures. Sports Health 2014;6:197-202.

Hootman JM, Dick R, Agel J. Epidemiology of collegiate injuries for 15 sports: summary and recommendations for injury prevention initiatives. J Athl Train 2007;42:311-319.

Jelinek HF, Khalaf K, Poilvet J, Khandoker AH, Heale L, Donnan L. The Effect of ankle support on lower limb kinematics during the Y-balance test using non-linear dynamic measures. Front Physiol 2019;10:935.

Kaminski TW, Hertel J, Amendola N, Docherty CL, Dolan MG, Hopkins JT, Nussbaum E, Poppy W, Richie D; National Athletic Trainers' Association. National Athletic Trainers' Association position statement: conservative management and prevention of ankle sprains in athletes. J Athl Train 2013;48:528-545.

Karandikar N, Vargas OO. Kinetic chains: a review of the concept and its clinical applications. PM R 2011;3:739-745.

Konor MM, Morton S, Eckerson JM, Grindstaff TL. Reliability of three measures of ankle dorsiflexion range of motion. Int J Sports Phys Ther 2012;7:279-287.

Lehr ME, Plisky PJ, Butler RJ, Fink ML, Kiesel KB, Underwood FB. Fieldexpedient screening and injury risk algorithm categories as predictors of noncontact lower extremity injury. Scand J Med Sci Sports 2013;23: e225-e232.

Lloyd RS, Oliver JL, Radnor JM, Rhodes BC, Faigenbaum AD, Myer GD. Relationships between functional movement screen scores, maturation and physical performance in young soccer players. J Sports Sci 2015;33:11-19.

Macrum E, Bell DR, Boling M, Lewek M, Padua D. Effect of limiting ankle-dorsiflexion range of motion on lower extremity kinematics and muscle-activation patterns during a squat. J Sport Rehabil 2012;21: 144-150.

Minick KI, Kiesel KB, Burton L, Taylor A, Plisky P, Butler RJ. Interrater reliability of the functional movement screen. J Strength Cond Res 2010; 24:479-486.

O'Connor FG, Deuster PA, Davis J, Pappas CG, Knapik JJ. Functional movement screening: predicting injuries in officer candidates. Med Sci Sports Exerc 2011;43:2224-2230.

Overmoyer GV, Reiser RF 2nd. Relationships between lower-extremity flexibility, asymmetries, and the $Y$ balance test. J Strength Cond Res 2015;29:1240-1247.

Sato K, Fortenbaugh D, Hydock DS, Heise GD. Comparison of back squat kinematics between barefoot and shoe conditions. Int J Sports Sci Coac 2013;8:571-578.

Sato N, Nunome H, Hopper LS, Ikegami Y. Ankle taping can reduce external ankle joint moments during drop landings on a tilted surface. Sports Biomech 2019;18:28-38.

Shaffer SW, Teyhen DS, Lorenson CL, Warren RL, Koreerat CM, Straseske CA, Childs JD. Y-balance test: a reliability study involving multiple raters. Mil Med 2013;178:1264-1270.

Simon J, Donahue M. Effect of ankle taping or bracing on creating an increased sense of confidence, stability, and reassurance when performing a dynamic-balance task. J Sport Rehabil 2013;22:229-233.

Stiffler MR, Pennuto AP, Smith MD, Olson ME, Bell DR. Range of motion, postural alignment, and LESS score differences of those with and without excessive medial knee displacement. Clin J Sport Med 2015; 25:61-66

Sutton KM, Bullock JM. Anterior cruciate ligament rupture: differences between males and females. J Am Acad Orthop Surg 2013;21:41-50.

Walaszek R, Chwała W, Walaszek K, Burdacki M, Błaszczuk J. Evaluation of the accuracy of the postural stability measurement with the Y-balance test based on the levels of the biomechanical parameters. Acta Bioeng Biomech 2017;19:121-128. 
Wilson BR, Robertson KE, Burnham JM, Yonz MC, Ireland ML, Noehren B. The relationship between hip strength and the $\mathrm{Y}$ balance test. J Sport Rehabil 2018;27:445-450.
Yammine K, Assi C. Neurovascular and tendon injuries due to ankle arthroscopy portals: a meta-analysis of interventional cadaveric studies. Surg Radiol Anat 2018;40:489-497. 